\title{
Beyond numbers: the NHS International Fellowship Programme in Psychiatry
}

\author{
Murad M. Khan
}

Professor and Chairman, Department of Psychiatry, Aga Khan University, PO Box 3500, Karachi 74800, Pakistan, email murad.khan@aku.edu

The issue of

recruiting in an

under-resourced

developing

country, where

skilled and trained

professionals are

in short supply but

where demand is

huge, has exposed

the duplicity

with which

many developed

countries interact

with developing

countries.

\section{The justification}

so far put forward

by proponents

of the IFP seems

to be devoid of

the reality that

exists in many

developing

countries.

\begin{abstract}
The recent controversy surrounding the National Health Service (NHS) International Fellowship Programme (IFP) for consultant psychiatrists (Patel, 2003) has raised a number of important issues. In particular, the issue of recruiting in an under-resourced developing country, where skilled and trained professionals are in short supply but where demand is huge, has exposed the duplicity with which many developed countries interact with developing countries. Although countries such as the UK are forever talking about strengthening the research and training capacity of these countries, they have no qualms about taking trained professionals for their own needs (Goldberg, 2003). Holsgrove (2005) has defended the IFP and tried to counter many of the arguments raised by those opposing it (Patel, 2003; Khan, 2004; Ndeiti et al, 2004).
\end{abstract}

\section{Pakistan}

The justification so far put forward by proponents of the IFP seems to be devoid of the reality that exists in many developing countries. Take the example of Pakistan, a South Asian developing country with a population of approximately I 50 million. The country has one of the lowest rates of literacy (35\%) in South Asia, has more than a third of its population living below the poverty line and health indicators that make sorry reading. All this is compounded by a precarious political system, a weak economy, rampant corruption and poor governance.

The mental health situation is even worse than the general one. Community-based prevalence studies for common mental disorders give very high rates (25-66\% for women; 10-44\% for men) (Mumford et al, 2000). These figures are higher even than those of other developing countries with a similar socio-economic background. When severe mental illnesses (approximately I-2\% prevalence), drug addiction (totalling some 3 million), children with psychiatric morbidity and mental retardation, and countless others with 'psychosomatic' illnesses are included in the total, the scale of the burden of mental health problems in Pakistan becomes apparent.

How can this be addressed? Resources are severely lacking. Health spending is less than 1\% of the gross national product. Mental health does not even have a separate budget. There are few psychiatric facilities in the country and few mental health professionals. There are negligible numbers of psychologists, mental health nurses or occupational therapists. Properly trained and qualified psychiatrists number only about 100-150. The reasons for this are partly historical (psychiatry is an unpopular specialty with a reputation for difficult postgraduate examinations), partly situational (there are very few training posts in the country) and partly ideological (few Pakistani psychiatrists abroad want to return).

\section{Six psychiatrists too many}

Psychiatrists, however, are a critical factor in driving the development of mental health services in the country. A few are now being trained in the UK, with generous financial packages and easy passage, by the NHS. Both Goldberg (2003) and Holsgrove (2005) make much of the fact that, of the 124 on the IFP, 'only six are from Pakistan' (Holsgrove, 2005). Can a country like Pakistan, with its abysmal mental health indicators, afford to lose even one psychiatrist? These are the best of the locally trained psychiatrists, desperately needed for the country's fledgling mental health system.

\section{Stringent scrutiny?}

Holsgrove (2005) has termed Khan's (2004) raising of issues around the IFS 'misleading'. He, in line with Goldberg (2003), argues that every application is 'stringently scrutinised' and only those that meet the 'College's high standards are recommended for Specialist Training Authority (STA) registration'. My personal contact with some of the selected candidates shows otherwise. I will restrict myself to only two examples.

First, a junior consultant from my department was accepted on the IFP only 20 months after gaining the FCPS (Fellowship of the College of Physicians and Surgeons, Pakistan). During those 20 months there was no formal higher psychiatric training. Compare this with a specialist registrar in the UK who has to undergo 3 years of training in an approved highertraining scheme for a Certificate of Completion of Specialist Training (CCST).

Second, a child psychiatrist of Pakistani origin, who trained in the USA but without board certification or any other postgraduate qualification, was also accepted on the IFP. This person was keen to know whether he could be considered for a faculty position 
at my university as he 'would be granted Membership of the Royal College of Psychiatrists (MRCPsych) as part of the IFP'. (To be considered for a faculty position at Aga Khan University one must possess the MRCPsych or US board certification or the Pakistani FCPS. This candidate does not possess any of these.)

Clearly, some of the 'stringent' procedures are not being followed.

\section{The duplicity of the NHS}

The NHS's duplicity is apparent in a number of ways. It denies recruiting in Pakistan, yet set up a recruitment stall at the World Psychiatric Association regional meeting in Lahore in September 2004, attended by many senior members of the College, including the President and the Dean. National Health Service (NHS) consultants have been holding regular recruitment meetings in five-star hotels in major cities of Pakistan. The NHS claims the IFP is for 2 years only, yet a consultant from my department recruited on the programme received a 5-year multiple-entry visa from the Home Office. There is no obligation to return home at the end of the 2-year period. With entry set at the consultant level, it is unlikely many will return.

\section{Critical mass}

In Pakistan, the IFP is increasingly viewed as yet another aspect of Western dominance. With little or no understanding of how precarious things are in mental health in Pakistan, the programme's supporters appear to have no qualms about draining the country's small pool of psychiatrists. In particular, they fail to understand that a developing country can afford to lose only some of its trained professionals once a critical mass of such people is reached. Sadly, with service provision at one psychiatrist per million population, Pakistan is far from achieving this.

\section{How can the problem be addressed?}

Britain and the NHS need to take note of the problems they have created. In particular, they need to reflect on their oft-stated rhetoric, reinforced by Goldberg (2003), of their intentions to improve mental health in countries like Pakistan. They should seriously consider the following.

\section{Local solutions for local problems}

Many of us in Pakistan who have worked in the NHS are baffled as to why many of the excellent staff-grade doctors are not being considered instead of the International Fellows. Many staff-grade doctors have excellent training behind them as well as Membership of the College and are far more competent than many International Fellows. Neither Goldberg (2003) nor
Holsgrove (2005) has found it important enough to comment on this.

\section{Funding to help psychiatrists return to Pakistan}

Such a fund should be accessible to Pakistani psychiatrists not only from the UK but also the USA, Australia and other Western countries. The fund could pay for the airfare of doctors and their families, as well as supplementing the psychiatrists' salaries, which are a fraction of what consultants earn in the West.

\section{A contribution to training}

For every psychiatrist recruited from Pakistan, the NHS should contribute to the training of at least 10 other psychiatrists. Ways in which this could be achieved include: funding more training posts in the country, upgrading some of the training posts, support for the establishment of sub-specialty units, and the funding of research training of local psychiatrists, with a stipend payable to the trainees.

\section{Beyond numbers}

Holsgrove's (2005) statement that 'in the past few years very considerable progress has been made both by the College of Physicians and Surgeons Pakistan and ... the Aga Khan University in improving medical education and examination' in Pakistan is patronising. If this improvement merely means more qualified psychiatrists will be lost to the NHS, then it will have been in vain. The statement clearly reflects the lack of understanding of the complexities that exist in the precarious healthcare systems of developing countries like Pakistan.

Above all, decision makers in the NHS and the Royal Colleges should get first-hand experience of what it is like to be poor and ill in Pakistan. Far removed from the reality of the situation in a poorly resourced, underdeveloped country, policy makers often become so short-sighted they have difficulty in looking beyond their figures. Increasing the numbers of consultant psychiatrists to make up the shortfall in the NHS by any means - even if this involves depriving other health services of this vital resource is all that matters to them.

This is immoral, unethical, short-sighted and devoid of any rationality.

\section{References}

Goldberg, D. (2003) The NHS International Fellowship Scheme for Consultant Psychiatrists. Newsletter of the Faculty of General and Community Psychiatry, 6 (spring), 5-6.

Holsgrove, G. (2005) The International Fellowship Programme: some personal thoughts. International Psychiatry, issue 7, 7-9.

Khan, M. M. (2004) The NHS International Fellowship Scheme in psychiatry: robbing the poor to pay the rich? Psychiatric Bulletin, 28, 435-437.

Mumford, D. B., Minhas, F. A., Akhtar, I., et al (2000) Stress and psychiatric disorder in urban Rawalpindi: community survey. British Journal of Psychiatry, 177, 557-562.

Ndeiti, D., Karim, S. \& Mubbashar, M. (2004) Recruitment of consultant psychiatrists from low- and middle-income countries. International Psychiatry, issue 6, 15-18.

Patel, V. (2003) Recruiting doctors from poor countries: the great brain robbery? BMJ, 327, 928.
In Pakistan, the IFP is increasingly viewed as yet another aspect of Western dominance.

With little or no understanding of

how precarious things are in mental health

in Pakistan, the programme's supporters appear to have no qualms about draining the country's small pool of psychiatrists. 